\title{
call for papers
}

JOM is seeking contributions on the following topics for 2019. For the full Editorial Calendar, along with author instructions, visit the JOM website at jom.tms.org.

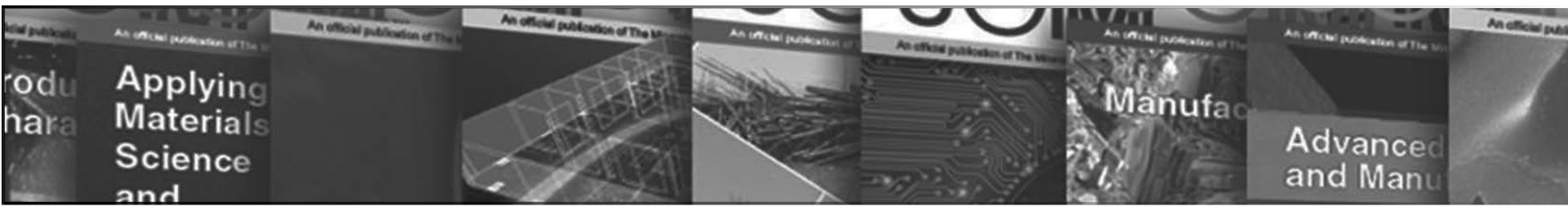

\section{April 2019: \\ Manuscript Deadline: November 1, 2018 \\ Topic: Deformation and Transitions at Grain Boundaries}

Scope: This topic will investigate how heterogeneous strains and transformations originating from grain boundaries can be characterized, analyzed, modeled, and used to ultimately predict continuum scale properties. From this perspective, all aspects of material production and service are covered, from initial solidification or consolidation to crack or void nucleation, as well as the processes by which damage coalescence becomes large enough to be modeled with continuum modeling strategies. Guest Editors: Saryu Fensin, Thomas Bieler, Shen Dillon, Jian Luo, and Douglas Spearot

Sponsor: Mechanical Behavior of Materials Committee

Topic: Protein-Based Structural Materials

Scope: .We invite contributions regarding characterization of natural protein materials, synthesis efforts including synthetic biology approaches, and computer simulations or modeling of such materials across the relevant length scales.

Guest Editor: Hannes Schniepp

Sponsor: Biomaterials Committee

\section{Topic: Advanced High-Strength Steels for Automobile}

Scope: Advanced high strength steels (AHSS) are particularly important to the automotive industry. The application of AHSS on automobiles is an effective way to reduce the weight of vehicles and therefore the fuel consumption while maintaining the passive safety. This special topic focuses on the latest developments in AHSS and invites contributions on the understanding of processmicrostructure-property relationships of AHSS.

Guest Editor: Mingxin Huang

Sponsor: Steels Committee
Topic: Characterization of Biodegradable Medical Materials

Scope: Present in vitro characterization methods for biomaterial assessment are unable to predict the in vivo degradation behavior and rates, critical for developing biodegradable implants. This special topic summarizes the challenges and provides insight into new developments in characterization methods applicable to biodegradable medical materials.

Guest Editors: Jaroslaw Drelich and Tolou Shokuhfar Sponsors: Materials Characterization Committee and Biomaterials Committee

\section{Topic: Interfacial Stresses and Strains: Effect on Electrical and Optical Properties}

Scope: Interfacing materials with dielectrics, metals, semiconductors, or alloys have been demonstrated to cause major effects in their electronic, optical, and electrical properties. Considering that interfaces are ubiquitous in all engineered devices establishes the need for a focused issue that covers the effect of stresses, light emission, carrier confinement, and carrier mobility, modeling of bandgap modulations and characterization techniques.

Guest Editors: Sufian Abedrabbo, N.M. Ravindra, and A.T. Fiory

Sponsor: Thin Films and Interfaces Committee

\section{May 2019: Manuscript Deadline: December 1, 2018 \\ Topic: Computational Approaches for Energy Materials and Processes}

Scope: Computational methods are extensively employed as indispensable tools for the design, development, and assessment of energy materials and processes. This topic focuses on modeling and simulation for improved functionality and performance of energy materials, as well as the development, optimization, and scale-up of energy processes. Guest Editors: Donna Guillen, Xiaobo Chen, and Douglas Spearot Sponsors: Energy Committee and Computational Materials Science and Engineering Committee 


\section{Topic: Aluminum and Magnesium: High Strength Alloys for Automotive and Transportation Applications}

Scope: This topic covers the development of light metalshigh strength alloys with a particular interest in automotive and transport applications. Broader submission aluminum alloys are also considered.

Guest Editor: Dmitry Eskin

Sponsors: Aluminum Committee and Magnesium Committee

\section{Topic: The Mechanics of Stresses and Strains} Engineered by Interfacing Materials and Their Effects Scope: Interfacing materials have dramatically altered their respective electronic, optical, and electrical properties. These modifications have been mainly caused by introduced lattice mismatches that are manifested in the form of stresses and strains. This topic examines the underlying mechanics of stress formation and its evolution by focusing on various characterization techniques, statistical models, and correlation to enhanced properties.

Guest Editors: Sufian Abedrabbo, Shen Dillon, Anthony T. Fiory, and Nuggehalli M. Ravindra

Sponsor: Thin Films and Interfaces Committee

\section{Topic: Metallurgical Kinetics}

Scope: Increased knowledge of the factors influencing reaction rates and driving mechanisms is beneficial for the control of industrial pyrometallurgical processes. This topic covers fundamentals of reaction kinetics and mass transport in multi-phase systems, and their application to designing materials processing operations and reactors.

Guest Editors: Camille Fleuriault and Joseph Grogan Sponsor: Pyrometallurgy Committee

\section{June 2019: Manuscript Deadline: January 1, 2019}

\section{Topic: Functional Nanomaterials for Energy Harvesting on a Flexible Substrate}

Scope: The scope of this topic will address nanomaterials for energy harvesting on a flexible substrate. Specifically, recent advances in the fabrication, characterization, and synthesis of energy harvesting nanomaterials, including piezoelectric nanowires, nanofibers, and thin film, for flexible substrate will be covered.

Guest Editors: Jiyong Chang and Chang-Yong Nam Sponsor: Nanomaterials Committee

Topic: Powder Materials for Energy Applications Scope: This topic will cover all aspects of powder material processing and property studies with energy applications as the main objective. It can include powder synthesis, forming (including additive manufacturing), sintering, and property evaluation. Papers from both industry and academics will be solicited.

Guest Editor: Kathy Lu

Sponsor: Powder Materials Committee

\section{Topic: Rare Metal Recovery from Secondary Resources}

Scope: The depletion of high quality ores coupled with rising extraction costs present critical challenges for extractive metallurgical industries. This topic focuses on the design and improvement of recycling processes of rare metal sources, Papers are invited on topics including rare metal recovery from secondary sources, aqueous processing, extraction and processing, platinum group metals, hydrometallurgy, environmental effects, and plant design.

Guest Editors: Sheikh Abdul Rezan, Takanari Ouchi, Hojong Kim, and Gisele Azimi

Sponsor: Hydrometallurgy and Electrometallurgy Committee

\section{July 2019: Manuscript Deadline: February 1, 2019}

Topic: Second-Phase Particles in Magnesium Alloys: Engineering for Properties and Performance

Scope: Alloy and process design to control second phase particle distribution is a key aspect of the future of magnesium alloys. This special topic is a holistic review of advances in the understanding of second-phase effects on magnesium alloy behavior.

Guest Editors: Victoria Miller and Petra Maier Sponsor: Magnesium Committee

Topic: Composition-Processing-MicrostructureProperty Relationships of Titanium Alloys

Scope: This topic seeks papers addressing emerging or novel uses of titanium, and investigations with an emphasis on the interplay between processing, microstructure, properties, and performance are encouraged. Titanium and titanium alloys, including beta, alpha+beta, intermetallic alloys as well as titanium matrix composites will be applicable.

Guest Editors: Benjamin M. Morrow, Carl J. Boehlert, Kayla L. Calvert, Yufeng Zheng, and Peter C. Collins Sponsor: Titanium Committee

\section{Topic: Urban Mining: Characterization and Recycling of Solid Wastes}

Scope: Since the solid wastes in urban areas have become significant environmental concerns, the recycling and reuse of these waste materials is attracting great attention both in the public and in the materials industry. This topic will focus on the characterization of urban waste materials and the effective extraction of metals from the materials.

Guest Editors: Mingming Zhang and Bowen Li Sponsors: Materials Characterization Committee and Recyclng and Environmental Technologies Committee

Topic: Advanced Manufacturing for Nuclear Energy Scope: To meet the demands for future nuclear energy, the nuclear industry is seeking new ways to manufacture equipment and components. Of interest for this topic are papers on additive manufacturing, advanced welding and cladding techniques, powder metallurgy, high performance concrete and rebar, surface modification, in-situ quality control, inspection, and advanced machining.

Guest Editors: Xiaoyuan Lou and David Gandy

Sponsor: Nuclear Materials Committee 